\title{
РОЛЬ ТРОФОЛОГИЧЕСКОГО СТАТУСА ПАЦИЕНТОВ ПРИ РАЗВИТИИ ЗАБОЛЕВАНИЙ ЖЕЛЧНОГО ПУЗЫРЯ
}

\section{THE ROLE OF THE TROPHOLOGICAL STATUS OF PATIENTS IN THE DEVELOPMENT OF GALLBLADDER DISEASES}

\author{
M. Moldoev \\ A. Turusbekova \\ Syed Ali Abbas Rahat \\ Z. Arynov \\ E. Baigashkayev \\ R. Kalmatov
}

Summary. The aim of ours study is to identify the influence of the trophological status on the development of the pathology of the biliary system, as well as the prevalence of this pathology and the general patterns of development with gastrointestinal diseases. We analyzed 133 patients with cholelithiasis since 2016, who received treatment at the Kara-Suu Territorial Hospital of Osh Region. Out of 133 patients: 128 patients underwent surgical treatment, 5 patients received conservative treatment. Out of 128 operated patients: 111 patients underwent laparoscopic cholecystectomy, 17 patients underwent laparotomy cholecystectomy.

Keywords: cholelithiasis, hepatoduodenal zone, cholecystectomy, trophological status, stomach pathology.

\section{Ввемение}

ж елчнокаменная болезнь (ЖКБ) относится к числу широко распространенных заболеваний среди всех заболеваний. Больные ЖКБ занимают первое место в хирургических стационарах среди больных с хроническими заболеваниями органов брюшной полости $(27,28)$. Эту болезнь справедливо считают “болезнью века" и "болезнью благополучия", имея в виду непосредственную связь ее развития с характером питания (23). Данные о распространенности хронического хо-
Молдоев Мурзали Ильязович

Преподаватель, Ошский государственный университет

mmi01@mail.ru

Турусбекова Акшоола Козманбетовна

К.м.н., Оиский государственный университет turusbekova.80@mail.ru

Саед Али Аббас Paxam

Преподаватель, Ошский государственный университет

alirahat7844@gmail.com

Арынов Замирбек Сапарбаевич

Преподаватель, Оиский государственный университет z.arynov80@mail.ru

Байгашкаев Эртегин Сапарбекович Преподаватель, Оиского государственного университета ertegin92@list.ru

Калматов Романбек Калматович Д.м.н., Ошский государственный университет krkmkmc@gmail.com

Аннотация. Цель является выявление влияния трофологического статуса на развитие патологии билиарной системы, а также распространенность данной патологии и общие закономерности развития с болезнями ЖКТ. Нами проанализированы 133 пациента с желчекаменной болезнью начиная с 2016 года, получивших лечение на базе Кара-Суйской территориальной больницы Ошской области. Из 133 больных: 128 пациентов подверглись оперативному лечению, 5 пациентов получили консервативное лечение. Из 128 прооперированных пациентов: 111 пациентам выполнена лапороскопическая холецистэктомия, 17 пациентам лапоротомная холецистэктомия.

Ключевые слова: желчекаменная болезнь, гепатодуоденальная зона, холецистэктомия, трофологический статус, патология желудка.

лецистита очень разноречивы, но прослеживается четкий рост числа случаев заболевания. Так в 1977-1979 гг., распространенность его составляла 3,9 на 1000 населения [29]. Заболеваемость хроническим бескаменным холециститом и хроническим каменным холециститом в 1995 г. в этой же территории уже составила 15,8 на 1000 населения [22]. Количество больных желчнокаменной болезнью неуклонно увеличивается [1.], как ни парадоксально, на фоне приобщения населения к достижениям индустриального общества: ведение малоподвижного образа жизни [2.], избыточное употребление пищи 
с большим количеством жиров [3.] и углеводов, низким содержанием свежих овощей, использование модифицированных продуктов, искусственных пищевых добавок, алкоголя [4.]. Установлена четкая зависимость функционального состояния желчного пузыря от количества жировой ткани - вероятность гипокинезии возрастает с увеличением удельного веса жировой ткани. По данным ученых количество больных растет вдвое каждые 10 лет. Среди пациентов 25-45 лет желчекаменная болезнь встречается у каждого пятого [5], что, несомненно, влияет на социально-экономическое состояние страны [6]. Для практического здравоохранения важны внедрение точных своевременных методов диагностики и лечения заболевания, чтобы уменьшить количество осложнений, в т.ч. оперативных пособий, что приведет к снижению социально-экономической нагрузки [7].

В Кара-Суйской ТБ количество больных с патологией желчного пузыря с каждым годом увеличивается. В 2016году было прооперировано 73 больных, 2018-году 87, за 9 мес 2020-года 85 больных.

В последние десятилетия достигнуты значительные успехи в диагностике и лечении ЖКБ, во многом обусловленные прогрессом в области разработки медицинской техники и фундаментальных наук. Благодаря этим достижениям во врачебной практике появились эффективные методы диагностики: ультразвуковое исследование, компьютерная томография, магнитно-ядерная томография, прямые методы контрастирования билиарного тракта. Наряду с этим не утратили своего значения такие методы исследования, как пероральная холецистография и внутривенная холеграфия. Несмотря на достижение в области диагностики заболеваний гепатобилиарной системы, существующие методы диагностики хронического холецистита не всегда дают объективную характеристику состояния желчевыводящих путей, печени и других смежных органов. Информативность рентгеноконтрасных методов исследований при хроническом бескаменном холецистите составляет $42 \%$ $(30,18)$ информативным методом диагностики хронического бескаменного холецистита является ультразвуковое исследование $(9,10,31,18)$. В последнее время с усовершенствованием ультразвуковых приборов УзИ чаще стали использовать для определения функционального состояния желчного пузыря (16,31). Л.М. Вейн, Б.В. Головский указывают на наибольшую диагностическую ценность клинического исследования больного, так как вспомогательные методы позволяют только уточнить характер процесса в билиарной системе, не раскрывая его характер, и, не определяя вида лечения [8].

Для диагностики патологию желчного пузыря в Кара-Суйской ТБ используют традиционные лабораторные, инструментальные методы исследования.
К традиционному лечению с помощью открытой холецистэктомии добавились методы лапароскопического вмешательства и малотравматические операции из минидоступа $(42,43,44,45,46)$. Более того, в распоряжении врачей появились неоперативные методы лечения: медикаментозное растворение и экстракорпоральное дробление камней. Широкий спектр диагностических и лечебных методов привел к пересмотру стратегии и тактики при ЖКБ. Естественно, возникла необходимость в оптимизации выбора диагностических исследований и метода лечения индивидуально для каждого пациента.

Необходимость тщательного обследования и в избавлении больного от ЖКБ продиктована не только возникающими приступами желчных колик, но и его сочетании с другими патологиями органов гепатобилиарной зоны, опасностью возникновения тяжелых осложнений (острого холецистита, механической желтухи, деструктивного панкреатита, острого гастрита, стрессовой язвы и др.), которые могут потребовать особый подход в диагностике и лечении, срочного оперативного вмешательства. $(38,39,40,41)$

Лечению должны подлежать больные с симптоматической ЖКБ, с латентно протекающей ее формой, при которой всегда существует угроза внезапного тяжелого осложнения патологического процесса. Рекомендация больному определенного метода лечения должна быть основана на оценке его физического состояния, характера заболевания, сопутствующих изменений в желчных протоках (камни, стриктура) и в соседних органах. Необходимую для этого информацию можно получить с помощью ряда инструментальных и лабораторных исследований.

Холецистэктомия не устраняет сложных патофизиологических основ, сформировавшихся при желчекамнеобразовании процессов пищеварения, которые реализуются впоследствии в нарушения депонирования, всасывания и переваривания пищи. Главным звеном нарушения функции гастродуоденальной зоны общепризнан дефицит желудочных, панкреатических ферментов.

В большинство случаев хронический холецистит сочетается с гастритом. Воспалению желудка при ЖКБ практически не уделяется внимания, об этом свидетельствует отсутствие публикаций по этому вопросу.

\section{Шель исслеАования}

Выявления распространенности ЖКБ, хронического холецистита, и ее связь с патологией желудка, основные закономерности возникновения и влияние трофологического статуса на развитие данной патологии. 


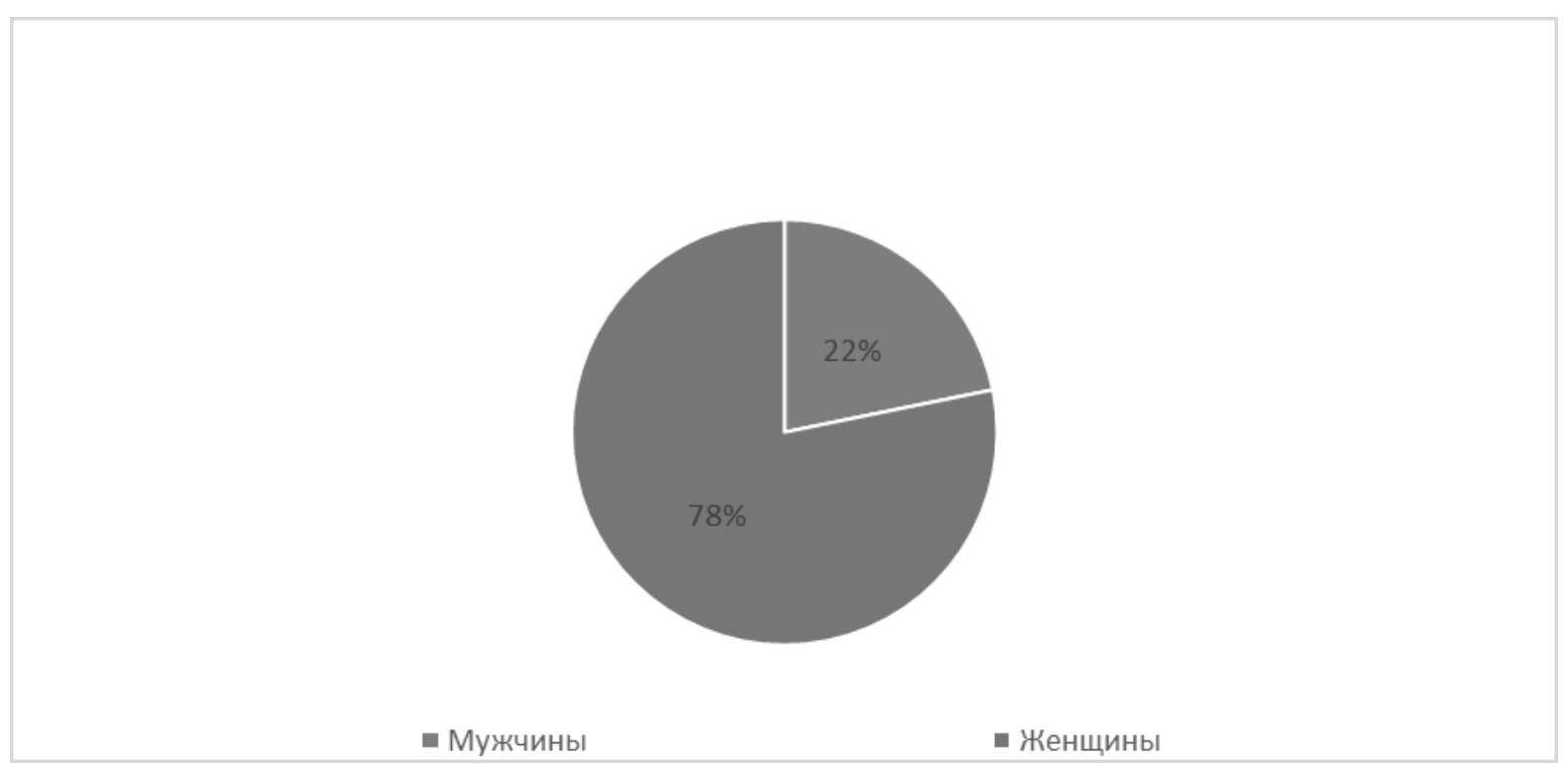

Рис. 1. Распределение по половому признаку

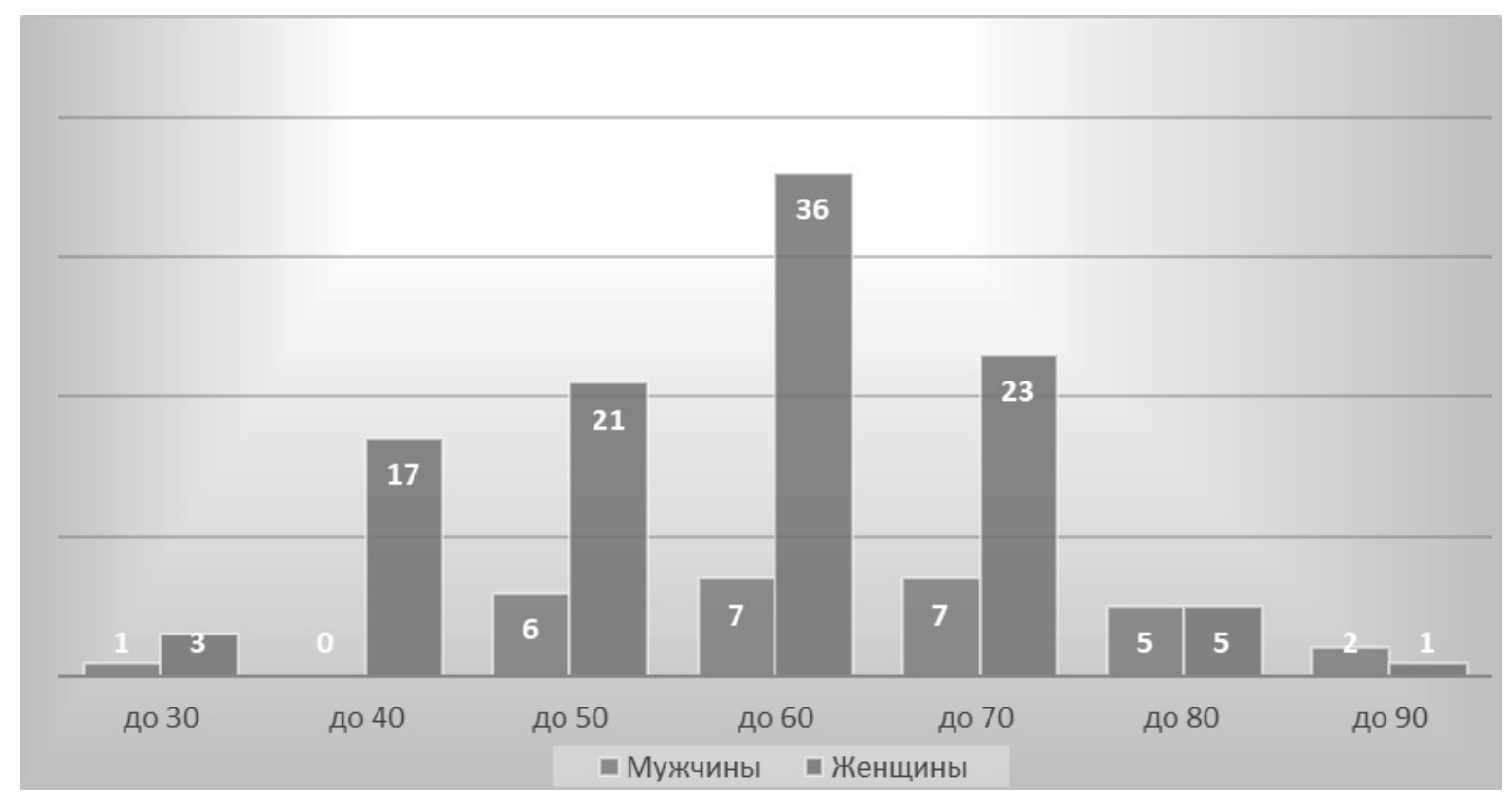

Рис. 2. Распределение по возрасту

\section{Материал и методы исследования}

Изучены истории болезни 133 больных с желчекаменной болезнью пролеченных в Кара-Суйской территориальной больнице в 2018-19 гг.

Из 133 больных:

1. 128 пациентов подверглись оперативному лечению,

2. 5 человек получили консервативное лечение.
Из 128 человек:

1. 111 пациентам выполнена лапороскопическая холецистэктомия,

2. 17 пациентам лапоротомная холецистэктомия, 1-му из них холецистэктомия и аппендэктомия одновременно, 1-му холецистохоледохотомия.

Больные распределены на группы по клиническим жалобам, половому признаку, возрасту, весу и росту. 
Таблица 1. Распределение пациентов по росту

\begin{tabular}{|c|c|c|c|c|c|c|c|c|}
\hline \multicolumn{9}{|c|}{ Распределение пациентов по росту } \\
\hline M & * & M & * & M & * & M & * & * \\
\hline 150-159cm & $130-139 \mathrm{~cm}$ & $160-169 \mathrm{~cm}$ & $140-149 \mathrm{~cm}$ & $170-179 \mathrm{~cm}$ & $150-159 \mathrm{~cm}$ & $180-189 \mathrm{~cm}$ & $160-169 \mathrm{~cm}$ & $170-179 \mathrm{~cm}$ \\
\hline 1 & 1 & 8 & 2 & 17 & 35 & 3 & 51 & 15 \\
\hline
\end{tabular}

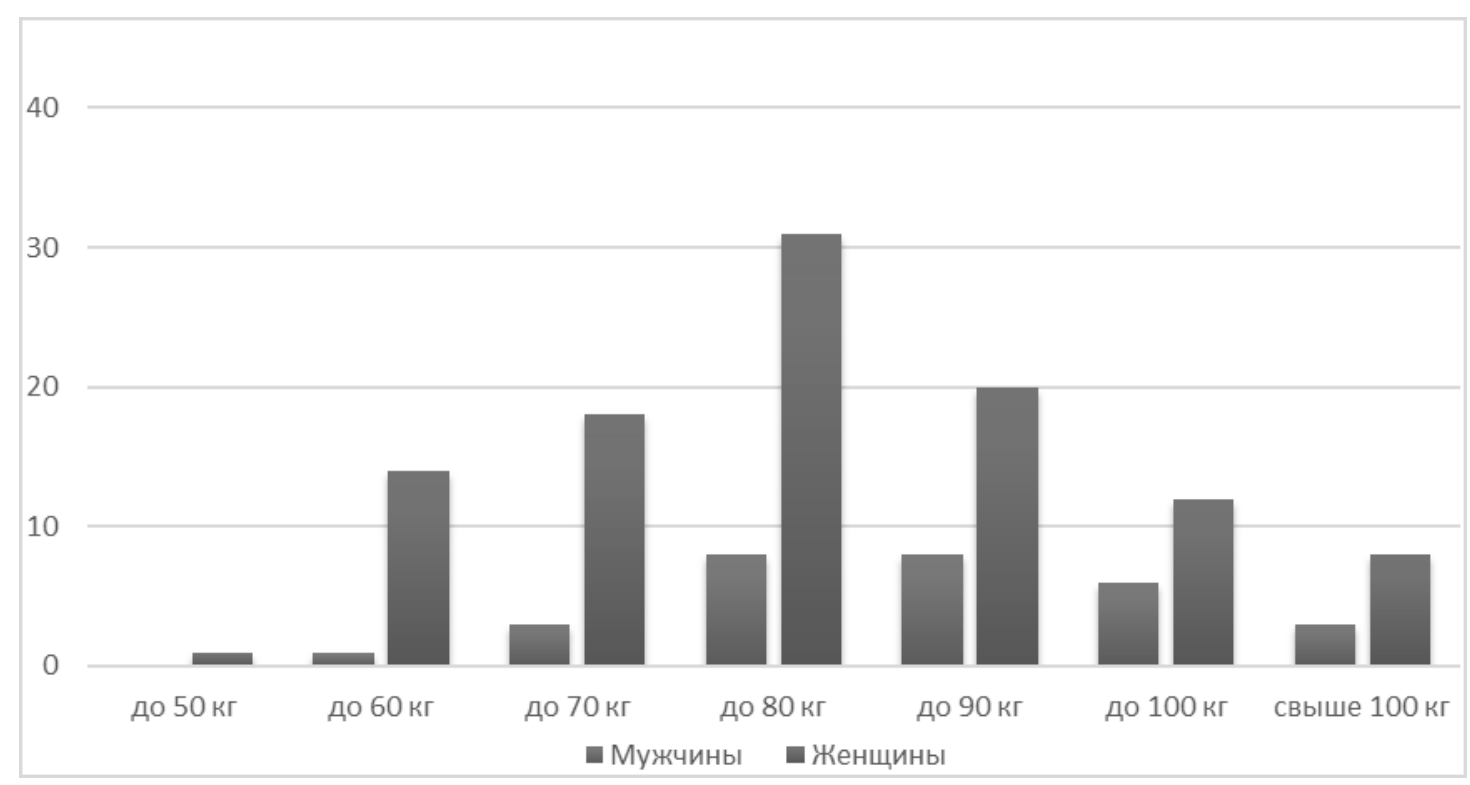

Рис. 3. Распределение по массе тела пациентов

\section{Результаты и их обсужление}

Клинические проявления хронического холецистита очень разнообразны, хотя в 17,77\% случаев заболевание имеет бессимптомное течение [34]. Ряд авторов считают, что заболевание, вообще не имеет специфичных высокочувствительных симптомов это, как правило, проявление патологии желудка.

У всех больных хроническим холециститом имеется диспепсический синдром. Л.П. Доценко и соавт. [34] считают, что часто он может проявляться только незначительными диспепсическими расстройствами в виде тошноты, отрыжки, запоров, чередующихся с поносами, которые преобладают в клинической картине заболевания.

После введения в практическое здравоохранение ультразвукового сканирования (УЗ) возросла значимо выявляемость хронического холецистита, их осложнений. УЗ в реальном масштабе является наиболее эффективным способом диагностики хронического холецистита, что обусловлено высокой степенью разрешающей его способности. При проведении УЗ возможен осмотр смежных органов и определение связи стенки ЖП и па- ренхимы печени [35]. Наличие воспаления ЖП и ЖВП подтверждается биохимическими и бактериологическими исследованиями [36].

Пациенты с клиническими жалобами на боль в правом подреберье составили 43 человек, пациенты с жалобами на боль в эпигастриальной области и правом подреберье - 90. Патогенез развития боли в эпигастральной области связан с такими осложнениями как: острый панкреатит, холедохолитиаз, обострение хронического гастрита и панкреатита.

На диаграмме представленной на рисунке 1, представлено распределение по половому различию, которое соответствует мировой тенденции указанной в литературе (11). Из 133 пациентов 29 мужчин и 104 женщин.

При анализе пациентов была выявлена следующая закономерность: среди мужчин до 50 лет выявлено 7 случаев болезни, а до 40 лет всего 1 случай. В то время после 50 лет количество заболевших увеличилось до 21 пациента. Такая же тенденция сохраняется у представителей женского пола: до 50 лет - 41 случай, после 50 лет 86 случаев, что представлено на рисунке 2 


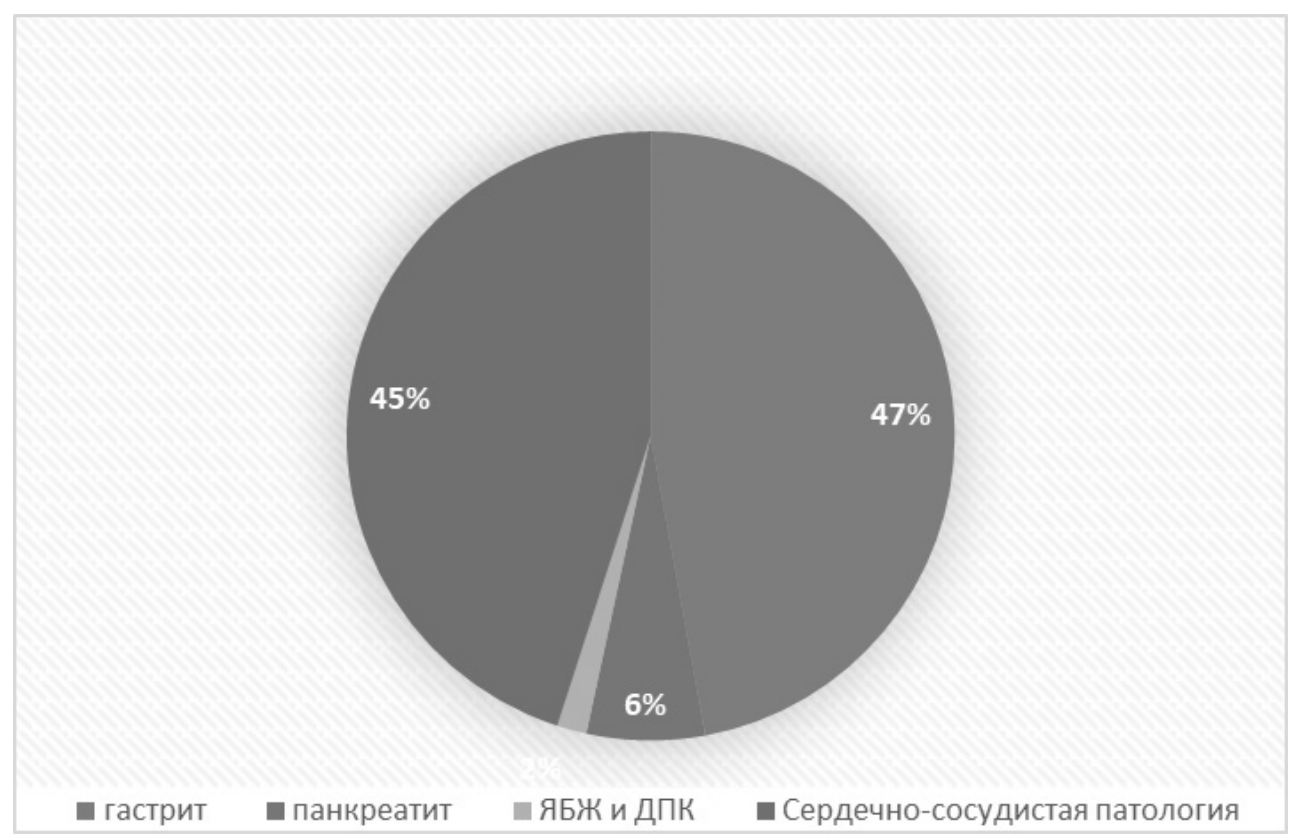

Рис. 4. Патология смежных органов при заболеваниях билаирной системы

\begin{tabular}{|l|l|l|l|l|} 
& гастрит & панкреатит & ЯБЖ и ДПК & $\begin{array}{l}\text { Сердечно-сосудистая } \\
\text { патология }\end{array}$ \\
\hline 1 & 90 & 12 & 3 & 86 \\
\hline
\end{tabular}

Из представленного на рисунке 3, распределения пациентов по массе тела видно, что наибольшее количество пациентов с патологией билиарной системы представлены в категории от 80 килограмм, как у мужчин, так и у женщин, что показывает прямую зависимость литообразования от индекса массы тела пациентов.

Анализируя конституциональные особенности пациентов с ЖКБ, в частности показатели роста, выявили следующие закономерности: у мужчин с ростом от 170179 см, выявляется чаще чем у других.

Среди пациенток высокие показатели распространения обнаруживаются у женщин с ростом от 150 до 169 сантиметров, что видны в таблице 1.

По данным истории болезни 133 больных, болеют холециститом чаще женщины чем мужчины, и их трофологический статус имеет больше значение чем их возраст, что также подтверждается литературными данными, которые указаны в данных С. Н. Стяжкиной, А. А. Валинурова, А.М. Шабардина, А.И. Аюпова (32).

Для постановления диагноза использованы следующие методы: клинико-анамнестические, лабораторные, ультразвуковое исследование, ЭКГ, пациентам старше 60 лет проведено рентгенологическое исследование ор- ганов грудной клетки. При госпитализации обязательно антропометрические данные измерялись.

Из 133 больных с анамнезом, наличие конкрементов в желчном пузыре, от 6 месяцев до 5 лет 67 больных, от 3 недель до 6 месяцев 23 больных и у многих на руках имелись неоднократные заключения УЗИ. У 43 пациентов было выявлено впервые, приступы повторялись в течении 3 недель.

Вне зависимости от формы холецистита, среди пациентов встречаются люди как трудоспособного возраста, так и пожилые.

Хроническая форма холецистита может обостриться в любое время, что невозможно предугадать и часто обостряется одновременно с хроническим гастритом. Как видно в материалах исследования, пациенты с жалобами на сочетанную боль в правом подреберья и эпигастральной области составляют почти около $50 \%$ от общего количества больных. Это говорит о том, что у больного имеется патология смежных органов, анализ, проведенный нами среди наших пациентов, представлен на рисунке 4. Таких пациентов следует обследовать не только на патологию желчного пузыря, но и на патологию желудка и ДПК, в частности проводить гастроскопию и исследовать функциональное состояние желудка. 
Во многих провинциальных больницах Кыргызстана пациенты с сочетанной патологией хронический холецистит с хроническим гастритом обследуются поверхностно. Пероральная холецистография, внутривенная холеграфия, гепатобилиосцинтиграфия проводятся не во всех больницах, лечение проводится эмпирически, что сказывается на социально-экономическом состоянии пациента и государства в целом. После проведенного оперативного лечения на основании УзИ данных, у таких больных может развиться обострение хронического гастрита и может развиться стрессовая язва с и без кровотечения. С учетом технической оснащенности территориальных больных рекомендуется УЗИ гепатобилиарной зоны, биохимическое исследование крови и лабораторно-инструментальное исследование желудка, так как, анатомо-функциональное изменения желудка и гепатобилиарной зоны может повлиять на результат оперативного лечения ЖКБ.

\section{Выво}

1. Холециститом в большинстве случаев болеют люди с большой массой тела, женщины чаще чем мужчины, и он сочетается с патологией гепатодуоденальной зоны. Изменение массы тела может привести к изменению химического состава желчи и функционального изменения желудка. Соответственно трофологический статус имеет значение.

2. Исследование качества жизни пациентов, страдающих желчекаменной болезнью, является объективным методом оценки проводимого лечения. На показатели качества жизни существенно влияют давность заболевания, а также своевременность обследования и лечения патологии желудка. Адекватное комплексное лечение сочетанных патологий значительно улучшает все показатели качества жизни при любом методе лечения ЖКБ и снижает «зависимость» пациентов от строгой диеты.

3. Пациенты с сочетанным болевым синдромом в эпигастриальной и правой подреберной областях будут обследованы на наличие патологию желчного пузыря и желудка, в частности гастроскопическое исследование и исследование секреторной функции его.

\section{ЛИТЕРАТУРА}

1. Лоранская И.Д. Функциональные расстройства билиарного тракта. М.: Форте принт, 2013.

2. Гальперин Э.И., Кузовлев Н. Ф., Чевокин А. Ю., Дюжева Т. Г., Гармаев Б. Г. Место каркасного дренирования в хирургии рубцовых стриктур желчных протоков на современном этапе.

3. Острый холецистит: учебное пособие для студентов лечебного и педиатрического факультетов / М. Н. Климентов, С. Н. Стяжкина, В. В. Проничев. Ижевск, 2015.

4. Руководство по хирургии желчных путей / под ред. Э. И. Гальперина, П. С. Ветшева. М.: Видар-М, 2006.

5. Кукош М.В., Власов А. П. Острый холецистит. М.: Наука, 2009.

6. Дадвани С. А. Желчнокаменная болезнь. М.: Видар-М, 2000.

7. Губергриц Н. Б. Желчнокаменная болезнь: от классики к современности // Гастроэнтерология. 2010. № 1. С. 83-95.

8. Вейн, А. М. Вегетативные и эмоциональные нарушения в патогенезе хронического холецистита /А.М. Вейн, Б. В. Головский //Терапевт, арх. - 1977. № 10. - C. 107-110.

9. Галкин В. А. Современные методы диагностики дискинезией желчного пузыря и некалькулезного холецистита. Тер.архив.-2001.—№ 8. — c. 37-38.

10. Дегтярева И. И. Хронический б.ескаменный холецистит.-Мед.газета «Здоровье Украины».— 2001.— № 7.

11. Стяжкина С.Н., Марьенко А.С., Хузина И. А. Проблемы лечения рака головки поджелудочной железы // Студенческий научный форум 2014. URL: http:// www. scienceforum.ru/2014/pdf/6571.pdf.

12. Иванченкова Р. А. Хронические заболевания желчевыводящих путей/ Р. А. Иванченкова. -М.: Атмосфера, 2006.-416

13. Болдин Б. В. Клиника, диагностика и лечение холестероза желчного пузыря// М 2000 Дисс. на соискание степени доктора мед. наук.

14. Голочевская В.С., Геня Л.П. Консервативное лечение больных желчекаменной болезнью препаратами хенодезоксихолевой и урсодезоксихолевой кислот// Клин. мед. 1992 т. 70 № 7/8 с. 60-63.

15. Григорьева И. Н. Основные факторы риска желчнокаменной болезни // Рос. журн. гастроэнтерол., гепатол., колопроктол.— 2007.— № 6.— С. 1722.

16. Аннаев А. А. Реджепова А. О. Сонография желчного пузыря.-Материалы 63-й науч.-практ.конф. ТГМИ. Ашхабад.— 1993.— с. 246.

17. Колпаков Н. А. Этиопатогенез, диагностика и хирургическое лечение желчнокаменной болезни у больных молодого возраста. // Дис. ... канд. мед. наук. 1993.

18. Топчиашвили 3.А., Гейниц А. В., Максименков А. В., Теплянин А.С. Холецистэктомия в сочетании с другими внутрибрюшными операциями.- Анналы хирургической гепатологии/ Том 8.— № 2.2003.— - с.-356-357.

19. Мансуров Х.Х.// 0 роли желчного пузыря в развитии холестеринового холелитиаза.// Здравоохранение Таджикистана. - 1983. - N2. - c. $14-20$.

20. Делюкина 0. В. Моторные дисфункции желчных путей и особенности биохимического состава желчи при билиарном сладже, методы их коррекции: Автореф. дисс. к-та мед. наук. Москва. — 2007. — 26 с. 
21. Булатов В.П., Камалова А. А., Хуснуллина Г. А. и др. Клинические, анамнестические, ультрасонографические и микроэкологические особенности желчнокаменной болезни в детском возрасте // Рос. вестн. перинатол. и педиатр. - 2009.— № 5. - C. 40-43.

22. Лузина, Е. В. Возможные механизмы развития заболеваний желчевыво-дящих путей в условиях Забайкалья /Е.В. Лузина, В. Н. Иванов, Ю. В. Пархоменко // Клинич. медицина, — 2000.— № 4.—C. 34-36.

23. Мельникова Н.В., Звенигородская Л. А., Овсянникова О. Н. и др. Атерогенная дислипидемия, неалкогольный стеатогепатит, методы лечения // Экспериментальная и клиничекая гастроэнтерология. 2007. № 1. С. 28-34.

24. Савельев В.С., В.А. Петухов, М. Р. Кузнецов. «Экономическая оценка рациональной ферментозаместительной терапии при панкреатите. Принципы и подходы». Доклад на Первой Всероссийской конференции «Организация, управление и финансирование учреждений здравоохранения в условиях социально-экономических реформ». Москва, 24-25 ноября 1999 г.

25. Цацаниди К.Н., Крендаль А. П. // Осложнения эндоскопической ретроградной панкреатохолангиографии и их профилактика // Пробл. хирургии желч. путей.-М. Медицина. - 1982. - c. 172-173.

26. Шендеров Б.А. //Медицинская микробная экология и функциональное питание.// Т. 1 и 2. Москва, Грант, 1988.

27. Вовк Е. И. Желчнокаменная болезнь в XXI веке: что нового? Лечащий врач. 2011; 2: 58-65.

28. Самсонов А. А. Хронический холецистит. Cons. Med. Гастроэнтерология. 2011; 2: 26-30.

29. Горчаков, Л. Г. Социально-гигиенические аспекты заболеваемости населения холециститом /Л.Г. Горчаков, Л. Г. Монаков // Здравоохранение Рос. Федерации. 1983.-№ 3.- С. 13-14.

30. Иванченкова, Р. А. Диагностические возможности математического анализа при оценке литогенности желчи / Р. А. Иванченкова // Клин, медицина.1990. - N4. - C. 86-88.

31. Иванченкова, Р. А. Патогенез холестероза желчного пузыря: обзор / Р. А. Иванченкова, А. В. Свиридов // Клин, медицина. - 2002. -№ 2. С. $14-19$.

32. С.Н. Стяжкина, А.А. Валинуров, А. М. Шабардин, А. И. Аюпов Хронический калькулезный холецистит-актуальное социально-экономическое заболевание//Журнал научных статьей// Здоровье и образование в XXI веке

33. Байкова, 0. А. Клинико-функциональные проявления дискинезий желчевыводящих путей у женщин / О. А. Байкова, Н. Н. Николаева // Актуальные вопросы биомедицинской и клинической антропологии: Матер.науч. конф.-Красноярск, 1997.— C. 117-118.

34. Доценко А.П., Чинченко Е. И., Квелашвили Д. В. Бескаменный холецистит. — Киев, 1990. — 104 с.

35. Ищенко Н. С. Роль УЗ-исследования в диспансеризации. Автореф. дис. ... канд. мед. наук. - М., 1990. — С. 8-16.

36. Витебский Я. Д. Патология желчных путей в свете клапанной гастроэнтерологии. — Курган, 1983. - 128 с.

37. Маржатка 3. Практическая гастроэнтерология. -Рига, 1976.- С. 125-136.

38. Глоуцал Л. Заболевания желчного пузыря и желчных путей. — Прага, 1967. — C. 85-97.

39. Гонтарь А. И. Рак желчного пузыря // Хирургия.-2001.-№ 3.-С.19-23.

40. Григорьев П.Я., Яковенко А. В. Клиническая гастроэнтерология. -М., 2001.- С. 318-335.

41. Меиджерицкий И. М. Секреты гастроэнтерологии. — Ростов-на-Дону, 1998. - С. 526-533.

42. Allen V.J., Borody N. 0., Bugliosi T.F. Repit dissolution of gallstones by methyl tertbutyl ether. Preliminary observation // New Tngl. J. Med. — 1985. Vol.312. -P. 217-234.

43. Bodnar S., Kelemen 0., Fule A. et al. Laparoscopic cholecystectomy in acute cholecystitis // Acta Chir. Hung. 1999: — Vol. 38; № 2. — P. $135-138$.

44. Bradea C., Niculescu D., Plesa C. et al. Laparoscopic cholecystectomy in non-lithiasis cholecystopathies. Colecistectomia laparoscopica in colecistopatiile nelitiazice // Rev. Med. Chir. Soc. Med. Nat. lasi. 2000. -Vol. 104,№ 4.-P. 91-93.

45. Hayakumo T., Nakajima Mi, Yasuda K. et al. Evaluation of percutaneous transhepatic gallbladder drainage (PTGBD) for, acute cholecystitis // Nippon-ShokakibyoGakkai-Zasshi: 1991.—Vol. 88, № 9.-P. 2119-2126.

46. Lau H., Lo C. Y., Patil N. G. et al. Early versus delayed-interval laparoscopic cholecystectomy for acute cholecystitis: a metaanalysis // Surg. Endosc. 2006. — Vol. 20, № 1.- P. 82-87.

47. Alawneh I. Acute noncalculous Cholecystitis in Burns // Brit. J. / Surg. — 1978. — № 4. — P. 243-245.

с Молдоев Мурзали Ильязович ( mmi01@mail.ru ), Турусбекова Акшоола Козманбетовна ( turusbekova.80@mail.ru )

Саед Али Аббас Рахат ( alirahat7844@gmail.com ), Арынов Замирбек Сапарбаевич ( z.arynov80@mail.ru ),

Байгашкаев Эртегин Сапарбекович ( ertegin92@list.ru ), Калматов Романбек Калматович ( krkmkmc@gmail.com ).

Журнал «Современная наука: актуальные проблемы теории и практики» 